Rafael Zardoya $\cdot$ Axel Meyer

\title{
The evolutionary position of turtles revised
}

Abstract Consensus on the evolutionary position of turtles within the amniote phylogeny has eluded evolutionary biologists for more than a century. This phylogenetic problem has remained unsolved partly because turtles have such a unique morphology that only few characters can be used to link them with any other group of amniotes. Among the many alternative hypotheses that have been postulated to explain the origin and phylogenetic relationships of turtles, a general agreement among paleontologists emerged in favoring the placement of turtles as the only living survivors of the anapsid reptiles (those that lack temporal fenestrae in the skull). However, recent morphological and molecular studies have radically changed our view of amniote phylogenetic relationships, and evidence is accumulating that supports the diapsid affinities of turtles. Molecular studies favor archosaurs (crocodiles and birds) as the living sister group of turtles, whereas morphological studies support lepidosaurs (tuatara, lizards, and snakes) as the closest living relatives of turtles. Accepting these hypotheses implies that turtles cannot be viewed any longer as primitive reptiles, and that they might have lost the temporal holes in the skull secondarily rather than never having had them.

Living turtles (order Testudines) are among the most striking and strangest tetrapods. Early on in their evolutionary history, these reptiles evolved distinctive shells as effective defense (Burke 1989). This innovation is probably the key to their evolutionary success and persistence, and has constrained the evolution of the rest of their morphology (Lee 1996). The general Baüplan of turtles has barely changed since the Triassic (200 MYA), yet their carapaces show a great variety of shapes that reflect adaptations to terrestrial, freshwater and marine

R. Zardoya (『)

Museo Nacional de Ciencias Naturales,

José Gutiérrez Abascal 2, 28006 Madrid, Spain

e-mail: mcnr154@pinar2.csic.es

Tel.: +34-91-4111328, Fax: +34-91-5645078

A. Meyer

Department of Biology, University of Konstanz,

78457 Konstanz, Germany niches (Pough et al. 1998). Based on the mechanism of retraction of their heads into the shell, extant turtles are classified into two main suborders, Cryptodira (turtles that bend their neck vertically) and Pleurodira (sidenecked turtles) (Shaffer et al. 1997). Cryptodires (approximately 200 species) have a worldwide distribution (though rare in Australia) whereas pleurodires (approximately 50 species) are currently found only in South America, Africa and Australia.

The exact phylogenetic position of turtles within the Amniota (reptiles, birds, and mammals) is the subject of a lively debate that dates back for over a century (Benton 1991). The current classification of amniotes is consistent with a single key morphological character, the presence and type of temporal fenestration of the skull (Fig. 1) (Günther 1867; Willinston 1917). Extant amniotes that show a completely roofed skull (i.e., turtles) are

Fig. 1 Temporal fenestration of the amniote skull. Anapsida: the skull of early amniotes shows complete dermal roofing of the temporal region. Turtles also have no true temporal openings. Diapsida: the skull of crocodiles and the tuatara has two temporal windows (shown in black) that accommodate jaw muscles. Birds, lizards, and snakes have modified the primitive diapsid pattern by the lost of one or more of the bone arches that defined the original two openings. Synapsida: the skull of mammals presents a single lower temporal hole (shown in black)

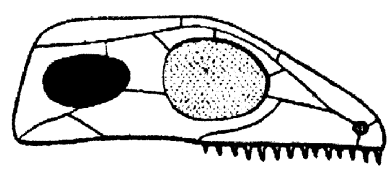

Synapsida

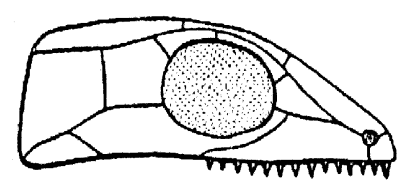

Anapsida

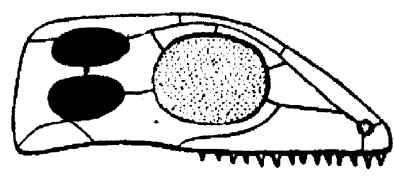

Diapsida 

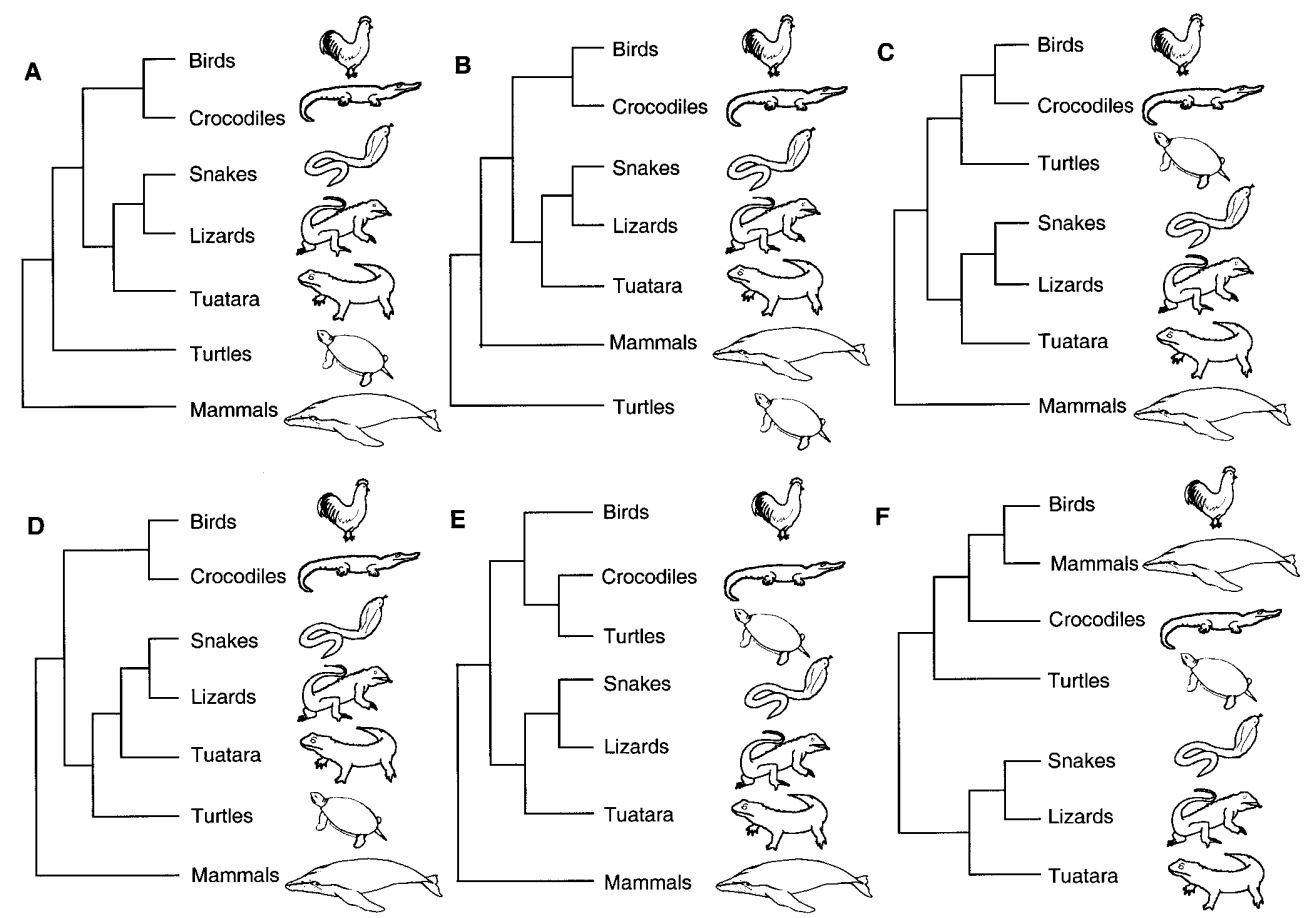

Fig. 2A-F Alternative hypotheses explaining the phylogenetic position of turtles within living amniotes. A Mammals are the most basal living amniotes. Turtles are the only living representatives of anapsid reptiles. Living diapsid reptiles include Lepidosauria (the tuatara, snakes, and lizards) and Archosauria (crocodiles and birds) (e.g. Laurin and Reisz 1995; Lee 1997). B Turtles represent the sister group of all other extant amniotes (Gaffney 1980). C Turtles have diapsid affinities, and are the sister group of Archosauria (e.g. Kumazawa and Nishida 1999; Zardoya and Meyer 2001). D Turtles have diapsid affinities, and are the sister group of Lepidosauria (e.g. deBraga and Rieppel 1997). E Turtles have archosaurian affinities, and are the sister group of crocodiles (Hedges and Poling 1999; Mannen and Li 1999; Cao et al. 2000). F The Haematothermia hypothesis: birds are the sister group of mammals (e.g. Gardiner 1993)

called anapsids. Those that have two fenestrae in the temporal region of the skull (tuatara, lizards, snakes, crocodiles, and birds) are the diapsids. Finally, living amniotes that possess a single lower temporal hole in their skulls (mammals) are the synapsids. According to the fossil record, the first branching event in amniote evolution appears to have separated the synapsids from anapsids and diapsids (Carroll 1988; Gauthier et al. 1988; Laurin and Reisz 1995; Caspers et al. 1996; Rieppel and deBraga 1996; Lee 1997; Reisz 1997; Cao et al. 1998; Zardoya and Meyer 1998). Within reptiles (Sauropsida), the anapsid condition shown by turtles is regarded by some as primitive with respect to the more advanced condition of diapsids (Fig. 2A) (e.g. Carroll 1988; Laurin and Reisz 1995; Lee 1997, 2001; Reisz 1997; Cao et al. 1998).

However, the traditional phylogenetic position of turtles as the only surviving representatives of anapsids is highly controversial (Benton 1991; Rieppel and deBraga 1996; deBraga and Rieppel 1997; Platz and Conlon 1997; Zardoya and Meyer 1998, 2001; Hedges and
Poling 1999; Kumazawa and Nishida 1999; Mannen and Li 1999; Rieppel and Reisz 1999; Cao et al. 2000). Alternative hypotheses, based either on morphological or on molecular evidence, have placed turtles as the most basal amniotes (Fig. 2B) (Gaffney 1980), as sister group of the Archosauria (crocodiles and birds) (Fig. 2C) (Hennig 1983; Platz and Conlon 1997; Zardoya and Meyer 1998, 2001; Kumazawa and Nishida 1999), as sister group of the Lepidosauria (tuatara, lizards, and snakes) (Fig. 2D) (Rieppel and deBraga 1996; deBraga and Rieppel 1997), as sister group of crocodiles (Fig. 2E) (Hedges and Poling 1999; Mannen and Li 1999; Cao et al. 2000), or basal to crocodiles and the Haematothermia clade (mammals and birds) (Fig. 2F) (Owen 1866; Gardiner 1982, 1993; Løvtrup 1985).

Living turtles are highly derived reptiles which also retain numerous amniote ancestral characters. It is difficult to estimate with confidence their phylogenetic affinities based on morphological data due to a general lack of shared derived characters with other amniotes and due to conflicting phylogenetic signal in different data sets (Rieppel and deBraga 1996). Moreover, the major lineages of amniotes (including turtles) show significantly different rates of molecular evolution, complicating phylogenetic inference based on molecular data (Kumazawa and Nishida 1999).

In recent years, new morphological and molecular data sets bearing on the phylogenetic position of turtles, and on amniote relationships, have accumulated. Most current phylogenetic information seems to be able to distinguish between some of the competing hypotheses and provides stunning new insights into our view of this long-standing phylogenetic issue. 


\section{Morphological evidence}

The monophyly of turtles is supported by many derived features such as their shell, strengthened skull, absence of teeth, and the position of the limb girdles inside the rib cage (Gaffney and Meylan 1988). Other undisputed monophyletic groups within the amniotes are: mammals (diagnosed by, e.g., possession of hair and mammary glands; Rowe 1988), squamates, i.e., lizards and snakes (diagnosed by, e.g., their skin and paired copulatory organs; Estes et al. 1988), crocodilians (diagnosed by, e.g., their posterior skull bones and elongated wrist bone; Benton and Clark 1988), and birds (diagnosed by, e.g., their feathers and furcula; Ostrom 1976). Furthermore, a close relationship of the tuatara (Sphenodon) and squamates to form the monophyletic clade Lepidosauria, and a sister group relationship of crocodilians and birds to form the monophyletic clade Archosauria are accepted generally among paleontologists. The debate about the position of turtles with respect to mammals, lepidosaurs, and archosaurs is still ongoing.

It is now widely accepted that mammals represent the sister group of all other living amniotes (Carroll 1988; Gauthier et al. 1988; Laurin and Reisz 1995; Rieppel and deBraga 1996; Lee 1997; Reisz 1997). However, in the past, two alternative hypotheses have been postulated. Gaffney (1980) proposed that mammals and diapsid reptiles (lepidosaurs and archosaurs) were sister groups because they shared a lower temporal hole in the skull and the development of a Jacobson's organ at some stage in ontogeny. Alternatively, a putative close relationship of birds and mammals, the Haematothermia hypothesis, as originally proposed by Owen (1866), has recently been revived (Gardiner 1982, 1993; Løvtrup 1985). Many authors have noticed that evidence in support of either hypothesis is rather weak and a number of characters supporting them are questionable (e.g., Gauthier et al. 1988). None of these latter hypotheses have been supported by new morphological or molecular phylogenetic data.

Hence, assuming that mammals are the outgroup to the rest of amniotes, turtles are typically placed basal to diapsid reptiles (Fig. 2A), as the sister group of Archosauria (Fig. 2C) or as the sister group of Lepidosauria (Fig. 2D).

Turtles as anapsids

Ever since Günther (1867) started classifying reptiles based on skull fenestration, many authors (Carroll 1988; Laurin and Reisz 1995; Lee 1997, 2001; Reisz 1997) have accepted the anapsid condition of turtles, i.e., they retain the primitively complete temporal roofing of the skull. Early studies proposed that turtles are derived either from extinct diadectids (Romer 1966) or captorhinids (Gaffney and Meylan 1988; Gauthier et al. 1988). At present, diadectids are thought to be basal to amniotes,

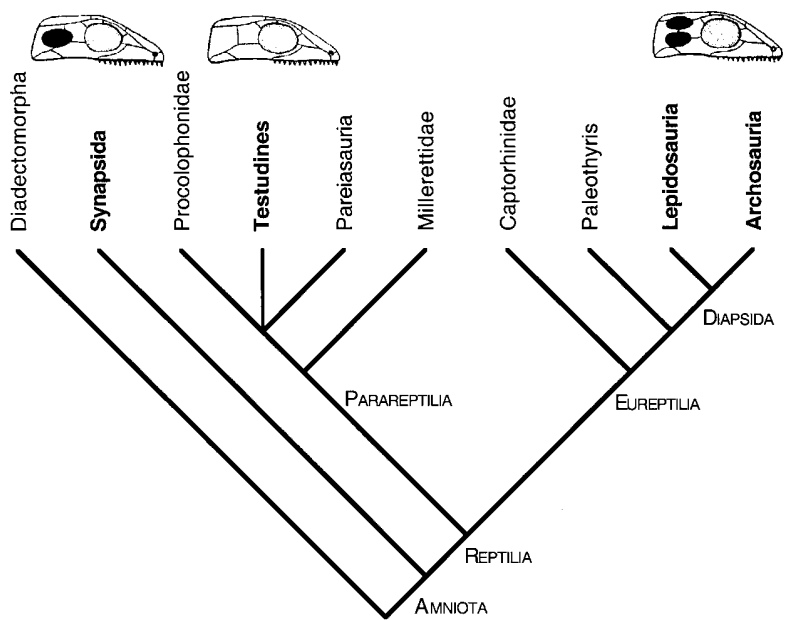

Fig. 3 Turtles as anapsid reptiles. Traditional phylogenetic hypotheses based on morphological and paleontological data place Synapsida (mammals and extinct relatives) as the most basal Amniota. Turtles (Testudines) are considered anapsid reptiles and are grouped either with extinct procolophonids (Laurin and Reisz 1995) or with extinct pareiasaurs (Lee 1997, 2001) in the Parareptilia clade. Living taxa are shown in bold

captorhinids are commonly placed basal to diapsids in the Eureptilia clade, and turtles are grouped either with procolophonids (Laurin and Reisz 1995) or with pareiasaurs (Gregory 1946; Lee 1995, 1996, 1997, 2001) in the Parareptilia clade (Fig. 3). If turtles are grouped with procolophonids or pareiasaurs, the origin of the lineage that led to turtles has to be placed in the Upper Permian (around 255 MYA) (Reisz 1997). However, the earliest fossil turtles such as Proganochelys are only from the Late Triassic (215 MYA) (Gaffney 1990; Rougier et al. 1995). Hence, both hypotheses imply the existence of a rather extensive gap of $40 \mathrm{Myr}$ (million years) in the fossil record (deBraga and Rieppel 1997). At least 14 shared derived characters that group together Upper Permian procolophonids, such as Procolophon and Hypsognathus, to testudines were proposed by Laurin and Reisz (1995). This grouping was supported by a $82 \%$ bootstrap value and a decay index of 5 (Laurin and Reisz 1995). On the other hand, up to seven features associated with the shell were found to relate turtles and dwarf pareiasaurs such as Nanoparia, Anthodon and Pumiliopareia (Lee 1996, 1997). Such a grouping was supported in a very recent morphological study by a bootstrap value of $93 \%$ and a decay index of 12 (Lee 2001). Lee (1996) proposed that the distinct carapace of turtles evolved gradually from the dermal armor of dwarf pareiasaurs which initially had a supporting function, and later in certain lineages become co-opted for protection (in a paradigmatic case of exaptation; Gould and Vrba 1982). Other striking unique traits of turtles would have arisen, influenced by the evolution of the shell, i.e., by correlated progression (Lee 1996). 


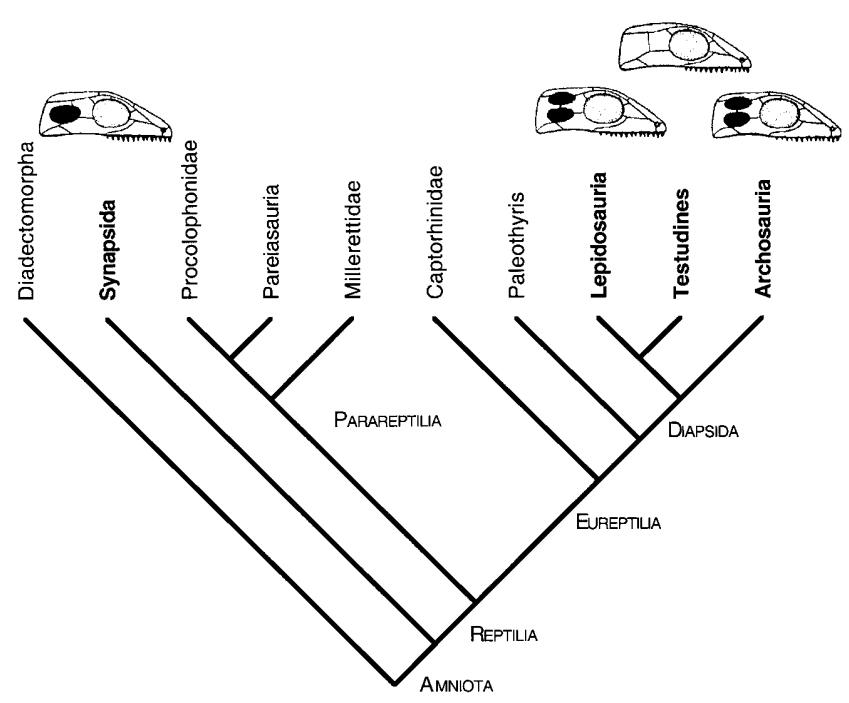

Fig. 4 Turtles as diapsid reptiles. Recent phylogenetic analyses (deBraga and Rieppel 1997) place turtles (Testudines) as advanced diapsid reptiles closely related to extinct Sauropterygia (marine plesiosaur and pliosaur reptiles). Lepidosauria (the tuatara, snakes, and lizards) are identified as the closest living relatives of turtles to the exclusion of Archosauria (crocodiles and birds). According to this hypothesis, turtles lost secondarily their original two openings in the tempora region of the skull. Living taxa are shown in bold

Turtles as diapsids

The traditional assumption that turtles were the only survivors of the anapsid lineage restricted most early cladistic analyses that tested turtle interrelationships exclusively to Paleozoic amniote taxa, i.e., excluded derived diapsid reptiles. However, a recent analysis based on 168 morphological characters that also included Mesozoic and living diapsids revealed that support for the anapsid affinities of turtles is rather weak (Rieppel and deBraga 1996; deBraga and Rieppel 1997). Instead, turtles were placed as advanced diapsid reptiles closely related to extinct Sauropterygia (marine plesiosaur and pliosaur reptiles) (Rieppel and deBraga 1996; deBraga and Rieppel 1997) (Fig. 4). In this phylogenetic analysis, Lepidosauria were identified as the closest living relatives of turtles (Rieppel and deBraga 1996; deBraga and Rieppel 1997) (Fig. 4). The Testudines+Sauropterygia clade was supported only by a $43 \%$ and two steps were needed to collapse it (deBraga and Rieppel 1997). Similarly, the Diapsida and Eureptilia clades (Fig. 4) were weakly supported by bootstrap values below 50\% (deBraga and Rieppel 1997). To explain this apparent lack of strong bootstrap support, the authors pointed out that their phylogenetic analysis showed a higher rate of homoplasy because of the large data set and numerous taxa (Rieppel and deBraga 1996; deBraga and Rieppel 1997; Rieppel and Reisz 1999; but see Wilkinson et al. 1997). The osteological data set of deBraga and Rieppel (1997) was recently revised and expanded by Lee (2001). The phylogenetic analysis of this expanded osteological data set recovered a single most parsimonious tree that supported the anapsid condition of turtles (Lee 2001). This result was highly dependent on the inclusion of fossil taxa in the phylogenetic analysis. When fossils were excluded, and the phylogenetic analysis was performed only with living taxa, three equally most parsimonious trees were recovered in which turtles were either placed as sister group of diapsids, or grouped with archosaurs, or grouped with lepidosaurs (Lee 2001).

Recent analyses show that it is the Sauropterygia that places turtles deep within the diapsids (Rieppel and Reisz 1999). Interestingly, there is morphological evidence that may place plesiosaurs and pliosaurs basal to the Archosauria (Merck 1997). Hence, it is possible that both turtles and sauropterygians could be closely related to the Archosauria rather than to the Lepidosauria. A close relationship of turtles and archosaurs had previously been proposed on the basis of neontological characters (e.g., deBeer 1937; Ax 1984; Løvtrup 1985; Gardiner 1993). However, a recent study showed that most, but not all, of the neontological characters that relate turtles to archosaurs were invalid (Rieppel 2000).

The hypothesis that turtles are crown-group diapsids implies that the anapsid condition of the turtle skull developed secondarily. In fact, Proganochelys (Gaffney 1990) and extant turtles show a squamosal configuration in the temporal region of the skull that does not match the primitive pattern found in Paleozoic anapsids, and it would be consistent with the former presence of a lateral temporal hole (deBraga and Rieppel 1997). It has been suggested that it might be possible that a dorsal expansion of the quadratojugal could have closed a putative fenestra in the ancestor of turtles (deBraga and Rieppel 1997). Given the very specialized body plan of turtles, it may not be too far-fetched to propose that the turtle skull is also highly derived (Carroll 1988). Apparently, the loss of the temporal skull window may be a more frequent event than previously thought. In fact, it has been demonstrated in several extinct reptiles, such as, e.g., some araeoscelid diapsids (deBraga and Rieppel 1997). The diapsid affinities of turtles may be also supported by developmental patterns of ossification which are shared by turtles and extant diapsids (Rieppel 1995). Furthermore, if turtles are diapsids, their ancestor likely had to evolve in the Lower to Middle Triassic (245-235 MYA). This evolutionary scenario shortens the gap in the fossil record between the origin of the turtle lineage and Proganochleys to less than $20 \mathrm{Myr}$ (deBraga and Rieppel 1997).

\section{Molecular evidence}

It has been suggested that molecular data may be helpful in resolving the morphological controversy on the phylogenetic position of turtles (Wilkinson et al. 1997). However, many phylogenetic analyses of relatively small molecular data sets were rather weak in their conclusions. Phylogenetic analyses of amino acid sequences from $\alpha$ 
A-crystallin, $\alpha$ - and $\beta$-hemoglobin, myoglobin, histone $\mathrm{H} 2 \mathrm{~B}$, cytochrome $c$, and insulin were unable to resolve the relationships of turtles, birds, and crocodiles (Hedges et al. 1990 and references therein). The Haematothermia hypothesis (Owen 1866; Gardiner 1993) (Fig. 2F) seemed plausible based on 18S rRNA evidence (Hedges et al. 1990). However, subsequent reanalyses of this nuclear data set (Hedges et al. 1990) with weighted parsimony (Marshall 1992), a total evidence approach that combined molecular and morphological data (Eernisse and Kluge 1993), and the use of a tree reconstruction method that takes into account the among-site rate variation of the rRNA molecule (Van de Peer et al. 1993), rejected the mammal+bird clade, and supported mammals as the sister group of all other living amniotes. More recently, larger molecular data sets have been collected, and the basal position of mammals among living amniotes has been firmly established (Hedges 1994; Caspers et al. 1996; Strimmer and von Haeseler 1996; Janke and Arnason 1997; Cao et al. 1998; Zardoya and Meyer 1998, 2001; Hedges and Poling 1999; Mannen and Li 1999; Mindell et al. 1999; Cao et al. 2000). However, recent phylogenetic analyses of relatively large mitochondrial and nuclear sequence data sets differ on the relative position of turtles with respect to diapsids (Lepidosauria and Archosauria).

\section{Mitochondrial evidence}

A maximum parsimony (MP) analysis of complete mitochondrial $12 \mathrm{~S}$ and $16 \mathrm{~S}$ rDNA sequences supported the traditional anapsid position of turtles, i.e., basal to lepidosaurs and archosaurs (Hedges 1994) (Fig. 2A). The same study, based on neighbor-joining (NJ) analysis, however, favored a sister group relationship between turtles and lepidosaurs with low bootstrap support (Hedges 1994) (Fig. 2D). A maximum likelihood (ML) analysis of the same molecular data set supported with high bootstrap values the anapsid nature of turtles (Strimmer and von Haeseler 1996; Cao et al. 1998) (Fig. 2A). However, these results appeared to be sensitive to taxon sampling (Zardoya and Meyer 1998), and obviously the phylogenetic method used. Further phylogenetic analyses (MP, $\mathrm{NJ}, \mathrm{ML}$ ) of the same genes with additional taxa (including representatives of the two major lineages of turtles, Pleurodira and Cryptodira) recovered a turtle+Archosauria clade supported by moderately high bootstrap values (Zardoya and Meyer 1998) (Fig. 2C). Alternative hypotheses [turtles as anapsids (Fig. 2A) or turtles as sister group of lepidosaurs (Fig. 2D)] could not be statistically rejected based on this data set (Zardoya and Meyer 1998).

A ML analysis (using the mtREV model; Adachi and Hasegawa 1996) of concatenated amino acid sequences of 12 complete mitochondrial protein-coding genes further supported the archosaurian affinities of turtles and statistically rejected alternative hypotheses (Kumazawa and Nishida 1999). The turtle+archosaurian clade was supported by a $100 \%$ bootstrap value (Kumazawa and Nishida 1999). A very recent and comprehensive ML analysis accounting for among-site rate variation, which combined the amino acid sequences of 12 mitochondrial proteins, and the nucleotide sequences of the two mitochondrial rRNA genes, also strongly supported the close relationship of turtles and archosaurs (Fig. 5A) (Cao et al. 2000). The phylogenetic analyses (with MP, NJ, and ML) of a molecular data set which included complete mitochondrial protein-coding, rRNA, and tRNA genes further supported the phylogenetic position of turtles as sister group of archosaurs (crocodiles+birds) (Zardoya and Meyer 2001) (Fig. 5B).

\section{Nuclear evidence}

Phylogenetic analyses (with MP, NJ, and ML) of a data set that combined the nucleotide sequences of the lactate dehydrogenase (LDH-A and LDH-B) and $\alpha$-enolase genes from several amniotes strongly supported crocodiles as the closest living relatives of turtles (Mannen and $\mathrm{Li}$ 1999) even to the exclusion of birds (Fig. 2E). A more comprehensive study that included amino acid sequences from 11 nuclear proteins also strongly supported $(100,99$, and $97 \%$ bootstrap values in the ML, NJ, and MP analyses, respectively) the turtle+crocodile clade (Fig. 2E) (Hedges and Poling 1999). However, three of those nuclear proteins ( $\alpha$ A-crystallin, $\alpha$-enolase, and calcitonin) supported individually a turtle+archosaurian grouping (Hedges and Poling 1999). These analyses did not include the tuatara (Sphenodon) because few genes have been sequenced in this species (Mannen and $\mathrm{Li}$ 1999; Hedges and Poling 1999). A smaller data set of sequences from four nuclear protein-coding genes for which sequences of the tuatara are available recovered a tree in which squamates were basal to an unresolved clade including tuatara, turtles, crocodiles, and birds (Hedges and Poling 1999). The nuclear 18S and 28S rRNA genes supported crocodiles as the closest living sister group of turtles (Hedges and Poling 1999) (Fig. 2E). A recent reanalysis of Hedges and Poling's (1999) data taking into account among-site rate variation and rate heterogeneity among genes also favored the turtle+ crocodile grouping (although with lower bootstrap support) (Cao et al. 2000). Furthermore, the combined mitochondrial and nuclear evidence favored crocodiles as the closest living relatives of turtles but could not statistically reject a turtle+archosaurian grouping (Cao et al. 2000).

A turtle+crocodilian clade is completely unorthodox from a morphological and paleontological perspective (osteology and soft anatomy clearly support a monophyletic Archosauria) (Gauthier et al. 1988; deBraga and Rieppel 1997). Similarly, there is strong morphological and paleontological evidence linking tuataras to squamates (Gauthier et al. 1988; deBraga and Rieppel 1997). Both crocodiles and turtles show significantly long branches which might introduce biases into the phyloge- 


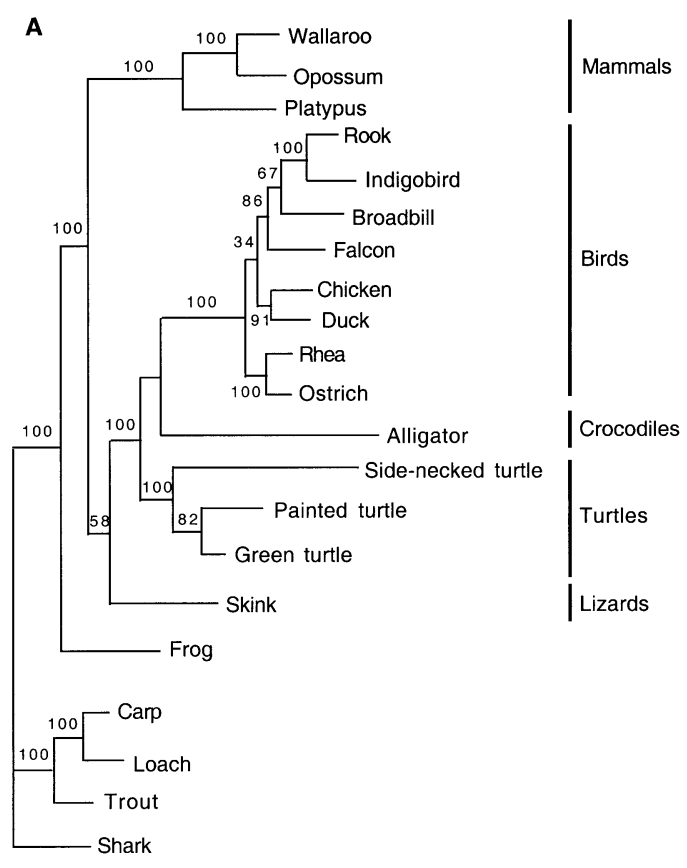

Fig. 5A, B Mitochondrial evidence supports a close relationship between turtles and archosaurs (crocodiles and birds). A A ML tree (using the mtREV-F model) estimated from the amino acid sequences of 12 mitochondrial proteins. Values above branches indicate local bootstrap probability (Cao et al. 2000). B 50\% majority rule consensus trees depicting living tetrapod relationships. Mitochondrial protein-coding, tRNA, and rRNA gene sequences were combined into a single data set that was subjected to MP (bootstrap values based on 500 bootstrap pseudo-replications upper of each triplet of numbers), NJ (bootstrap values based on 500 bootstrap pseudo-replications in the middle of each triplet of numbers), and ML (quartet puzzling support values based on 1,000 puzzling steps lower of each triplet of numbers) analyses. The phylogenetic analysis of the amino acid sequence of the pancreatic polypeptide also support the turtle+archosaurs clade (Platz and Conlon 1997). Other nuclear evidence seems to support a turtle+crocodilian clade (Hedges and Poling 1999; Cao et al. 2000)

netic analyses (see also Lee 2001 for other problems that may affect phylogenetic analyses of reptile molecular data). Hence, the molecular evidence favoring a turtle+crocodile clade needs to be treated as tentative, and clearly more nuclear data are needed to address this question.

In agreement with mitochondrial evidence, MP analysis of the pancreatic polypeptide at the amino acid level supports archosaurians as the living sister group of turtles (Platz and Conlon 1997). Several other studies clustered turtles with archosaurs rather than with lepidosaurs (Fitch and Margoliash 1967; Fushitani et al. 1996; Mannen et al. 1997; Gorr et al. 1998; Grishin 1999). However, these studies were based on rather small nuclear sequence data sets, some were based on gene families with complex paralogy relationships (Fushitani et al. 1996; Mannen et al. 1997; Gorr et al. 1998), and some did not include representatives of all the main lineages of amniotes (Fitch and Margoliash 1967; Grishin 1999). Therefore, the results of these studies are typically in-

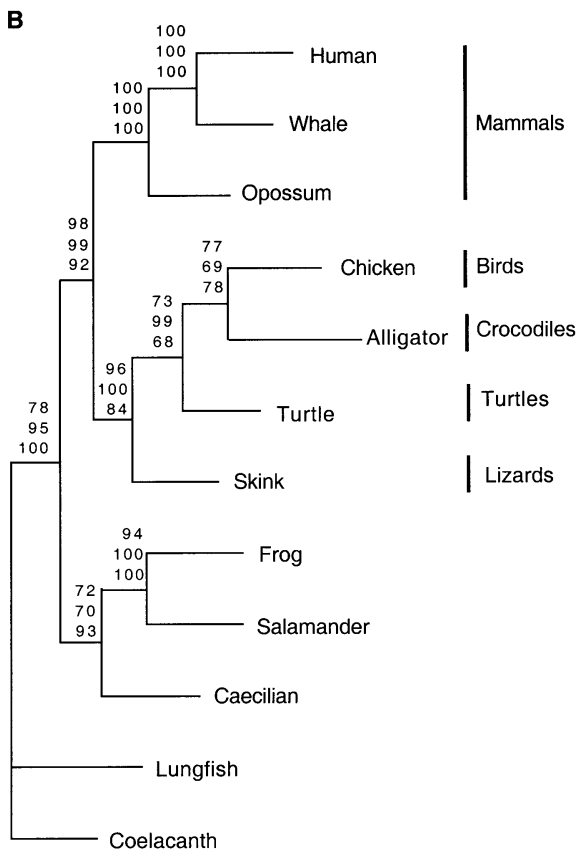

consistent, not statistically supported, and hence difficult to interpret.

\section{Conclusions}

Traditionally, textbooks present turtles as primitive reptiles that are the only living representatives of anapsids (Romer 1966; Carroll 1988; Pough et al. 1998). According to the classical hypothesis, turtles would have diverged either from procolophonids (Laurin and Reisz 1995) or pareiasaurs (Gregory 1946; Lee 1995, 1996, 1997, 2001), i.e., extinct parareptiles. However, recent molecular (Zardoya and Meyer 1998, 2001; Hedges and Poling 1999; Kumazawa and Nishida 1999; Mannen and Li 1999; Cao et al. 2000) and morphological (Rieppel and deBraga 1996; deBraga and Rieppel 1997) evidence seriously challenges this classical view, and place turtles deep within the diapsids.

Mitochondrial evidence clearly favors a close relationship of turtles to archosaurs (crocodiles and birds) (Kumazawa and Nishida 1999; Zardoya and Meyer 1998, 2001; Cao et al. 2000). Nuclear evidence seems to support a turtle+crocodile grouping (Hedges and Poling 1999; Mannen and Li 1999; Cao et al. 2000). A combined analysis of mitochondrial and nuclear data cannot reliably discriminate between both hypotheses, but clearly rejects the anapsid condition of turtles (Cao et al. 2000).

On the other hand, new morphological evidence links turtles to lepidosaurs (tuatara, lizards, and snakes) (deBraga and Rieppel 1997). This evidence depends on the relative position of Sauropterygia (Rieppel and Reisz 1999), which have recently been proposed to be closely related to archosaurs (Merck 1997). However, it is important to note that a recent reanalysis of deBraga and 
Rieppel's (1997) data seems to favor the anapsid condition of turtles (as sister group of pareiasaurs), and statistically rejects the putative diapsid affinities of turtles (Lee 2001). This result is dependent on the inclusion of fossil taxa in the phylogenetic analysis. Moreover, a total evidence analysis, including mitochondrial and morphological data, seems also to group turtles with anapsid parareptiles (Lee 2001). The molecular and morphological combined data set can statistically reject a turtle+lepidosaurian grouping but not a turtle+archosaurian sister group relationship (Lee 2001).

The synapomorphies uniting turtles and diapsids are distributed all over the skeleton (Rieppel and Reisz 1999). Therefore, turtles can no longer be assumed to provide the ancestral condition against which to interpret comparative studies involving reptiles (Rieppel and deBraga 1996). A phylogenetic position of turtles within Diapsida would imply that turtles had windows in the temporal region of the skull which were secondarily closed. The true anapsid condition would be restricted to Parareptilia fossils and the diapsid condition would be a shared derived character of all living reptiles, indicating their monophyly.

Acknowledgements We thank Michael S. Y. Lee and an anonymous reviewer for insightful comments on an earlier version of the manuscript. R.Z. was sponsored by a postdoctoral contract of the Ministerio de Educacion y Cultura of Spain. This work received partial financial support through grants from the Lion Foundation, the Deutsche Forschungsgemeinschaft, the University of Konstanz, and the US National Science Foundation (DEB9615178) to A.M.

\section{References}

Adachi J, Hasegawa M (1996) Model of amino acid substitution in proteins encoded by mitochondrial DNA. J Mol Evol 42: 459-468

Ax P (1984) Das phylogenetische System. G Fischer, Stuttgart

Benton MJ (1991) Amniote phylogeny. In: Schultze HP and Trueb L (eds) Origins of the major groups of tetrapods: controversies and consensus. Cornell University Press, Ithaca, pp 317-330

Benton MJ, Clark JM (1988) Archosaur phylogeny and the relationships of the Crocodylia. In: Benton MJ (ed) The phylogeny and classification of the tetrapods, vol 1. Amphibians, reptiles, birds. Clarendon Press, Oxford, pp 295-338

Burke AC (1989) Development of the turtle carapace: implications for the evolution of a novel bauplan. J Morphol 199:363-378

Cao Y, Adachi J, Hasegawa M (1998) Comment on the quartet puzzling method for finding maximum-likelihood tree topologies. Mol Biol Evol 15:87-89

Cao Y, Sorenson MD, Kumazawa Y, Mindell DP, Hasegawa M (2000) Phylogenetic position of turtles among amniotes: evidence from mitochondrial and nuclear genes. Gene 259: $139-148$

Carroll RL (1988) Vertebrate paleontology and evolution. Freeman, New York

Caspers GJ, Reinders GJ, Leunissen JA, Watte J, Jong WW de (1996) Protein sequences indicate that turtles branched off from the amniote tree after mammals. J Mol Evol 42:580-586

deBeer GS (1937) The development of the vertebrate skull. Clarendon Press, Oxford

deBraga M, Rieppel O (1997) Reptile phylogeny and the interrelationships of turtles. Zool J Linn Soc 120:281-354
Eernisse DJ, Kluge AG (1993) Taxonomic congruence versus total evidence, and amniote phylogeny inferred from fossils, molecules, and morphology. Mol Biol Evol 10:1170-1195

Estes R, Queiroz K de, Gauthier J (1988) Phylogenetic relationships within Squamata. In: Estes R, Pregill G (eds) The phylogenetic relationships of the lizard families. Stanford University Press, Stanford, pp 119-281

Fitch WM, Margoliash E (1967) Construction of phylogenetic trees. Science 155:279-284

Fushitani K, Higashiyama K, Moriyama EN, Imai K, Hosokawa K (1996) The amino acid sequences of two $a$ chains of hemoglobins from Komodo dragon Muanus komodensis and phylogenetic relationships of amniotes. Mol Biol Evol 13:10391043

Gaffney ES (1980) Phylogenetic relationships of the major groups of amniotes. In: Panchen AL (ed) The terrestrial environment and the origin of land vertebrates. Academic Press, London, pp 593-610

Gaffney ES (1990) The comparative osteology of the Triassic turtle Proganochelys. Bull Am Mus Nat Hist 194:1-263

Gaffney ES, Meylan PA (1988) A phylogeny of turtles. In: Benton MJ (ed) The phylogeny and classification of tetrapods, vol 1. Clarendon Press, Oxford, pp 157-219

Gardiner BG (1982) Tetrapod classification. Zool J Linn Soc $74: 207-232$

Gardiner BG (1993) Haematothermia: warm-blooded amniotes. Cladistics 9:369-395

Gauthier J, Kluge AG, Rowe T (1988) Amniote phylogeny and the importance of fossils. Cladistics 4:105-209

Gorr TA, Mable BK, Kleinschmidt T (1998) Phylogenetic analysis of reptilian hemoglobins: trees, rates, and divergences. J Mol Evol 47:471-485

Gould SJ, Vrba ES (1982) Exaptation - missing term in the science of form. Paleobiology 8:4-15

Gregory WK (1946) Pareiasaurs versus placodonts as near ancestors to turtles. Bull Am Mus Nat Hist 86:275-326

Grishin NV (1999) A novel approach to phylogeny reconstruction from protein sequences. J Mol Evol 48:264-273

Günther AC (1867) Contribution to the anatomy of Hatteria (Rhynchocephalus Owen). Trans R Soc Lond 157:595-629

Hedges SB (1994) Molecular evidence for the origin of birds. Proc Natl Acad Sci USA 91:2621-2624

Hedges SB, Poling LL (1999) A molecular phylogeny of reptiles. Science 283:998-1001

Hedges SB, Moberg KD, Maxson LR (1990) Tetrapod phylogeny inferred from $18 \mathrm{~S}$ and $28 \mathrm{~S}$ ribosomal RNA sequences and a review of the evidence for amniote relationships. Mol Biol Evol 7:607-633

Hennig W (ed) (1983) Stammesgeschichte der Chordaten. P Parey, Hamburg, pp 132-139

Janke A, Arnason U (1997) The complete mitochondrial genome of Alligator mississipiensis and the separation between recent Archosauria (Birds and crocodiles). Mol Biol Evol 14:12661272

Kumazawa Y, Nishida M (1999) Complete mitochondrial DNA sequences of the green turtle and blue-tailed mole skink: statistical evidence for archosaurian affinity of turtles. Mol Biol Evol 16:784-792

Laurin M, Reisz RR (1995) A reevaluation of early amniote phylogeny. Zool J Linn Soc 113:165-223

Lee MSY (1995) Historical burden in systematics and the interrelationships of 'parareptiles'. Biol Rev 70:459-547

Lee MSY (1996) Correlated progression and the origin of turtles. Nature 379:812-815

Lee MSY (1997) Pareiasaur phylogeny and the origin of turtles. Zool J Linn Soc 120:197-280

Lee MSY (2001) Molecules, morphology, and the monophyly of diapsid reptiles. Contrib Zool 70 (in press)

Løvtrup S (1985) On the classification of the taxon Tetrapoda. Syst Zool 34:463-470

Mannen H, Li SL (1999) Molecular evidence for a clade of turtles. Mol Phylogenet Evol 13:144-148 
Mannen H, Tsoi SC, Krushkal JS, Li WH, Li SS (1997) The cDNA cloning and molecular evolution of reptile and pigeon lactate dehydrogenase. Mol Biol Evol 14:1081-1087

Marshall CR (1992) Substitution bias, weighted parsimony, and amniote phylogeny as inferred from 18S rRNA sequences. Mol Biol Evol 9:370-373

Merck J (1997) A phylogenetic analysis of the Euryapsid reptiles. J Vertebr Paleontol Suppl 17:65A

Mindell DP, Sorenson MD, Dimcheff DE, Hasegawa M, Ast JC, Yuri T (1999) Interordinal relationships of birds and other reptiles based on whole mitochondrial genomes. Syst Biol 48:138-152

Ostrom JH (1976) Archaeopteryx and the origin of birds. Biol J Linn Soc 8:91-182

Owen R (1866) On the anatomy of vertebrates. I. Longmans and Green, London

Platz JE, Conlon JM (1997) Reptile relationships turn turtle ... and turn back again. Nature 389:246

Pough FH, Janis CM, Heiser JB (1998) Vertebrate life. Prentice Hall, Upper Saddle River, N.J., pp 342-367

Reisz RR (1997) The origin and early evolutionary history of amniotes. Trends Ecol Evol 12:218-222

Rieppel O (1995) Studies on skeleton formation in reptiles: implications for turtle relationships. Zoology 98:298-308

Rieppel O (2000) Turtles as diapsid reptiles. Zool Scr 29:199-212

Rieppel O, deBraga M (1996) Turtles as diapsid reptiles. Nature 384:453-455

Rieppel O, Reisz RR (1999) The origin and early evolution of turtles. Annu Rev Ecol Syst 30:1-22
Romer AS (1966) Vertebrate paleontology, 3rd edn. University of Chicago Press, Chicago

Rougier GW, Fuente MS de la, Arcucci AB (1995) Late Triassic turtles from south America. Science 268:855-858

Rowe T (1988) Definition, diagnosis and origin of Mammalia. J Vertebr Paleontol 8:241-264

Sefton M, Sanchez S, Nieto MA (1998) Conserved and divergent roles for members of the Snail family of transcription factors in the chick and mouse embryo. Development 125:3111-3121

Shaffer HB, Meylan P, McKnight ML (1997) Tests of turtle phylogeny: molecular, morphological, and paleontological approaches. Syst Biol 46:235-268

Strimmer K, Haeseler A von (1996) Quartet puzzling: a quartet maximum-likelihood method for reconstructing tree topologies. Mol Biol Evol 13:964-969

Van de Peer Y, Neefs JM, Rijk P de, Wachter R de (1993) Reconstructing evolution from eukaryotic small-ribosomal-subunit RNA sequences: calibration of the molecular clock. J Mol Evol 37:221-232

Wilkinson M, Thorley J, Benton MJ (1997) Uncertain turtle relationships. Nature 387:466

Willinston SW (1917) The phylogeny and classification of reptiles. J Geol 25:411-421

Zardoya R, Meyer A (1998) Complete mitochondrial genome suggests diapsid affinities of turtles. Proc Natl Acad Sci USA 95:14226-14231

Zardoya R, Meyer A (2001) On the origin of and phylogenetic relationships among living amphibians. Proc Natl Acad Sci USA 98 (in press) 